\title{
Domestic Triatoma sanguisuga-Human Exposure in the South Carolina Coastal Region
}

\author{
Kyndall C. Dye-Braumuller, ${ }^{1 \star}$ Chris L. Evans, ${ }^{2}$ Mary K. Lynn, ${ }^{1}$ Colin J. Forsyth, ${ }^{3}$ Claudia Gomez, ${ }^{4}$ and Melissa S. Nolan ${ }^{1}$ \\ ${ }^{1}$ Laboratory of Vector-Borne and Zoonotic Diseases, Arnold School of Public Health, University of South Carolina, Columbia, South Carolina; \\ ${ }^{2}$ South Carolina Department of Health and Environmental Control, Bureau of Environmental Health Services, Columbia, South Carolina; ${ }^{3}$ Chagas \\ Treatment Access Project, Drugs for Neglected Diseases Initiative-North America, New York, New York; ${ }^{4}$ Vector-Transmitted Diseases, \\ Department of Santander, Colombia
}

\begin{abstract}
A collaborative investigation was initiated in rural coastal South Carolina in response to a reported triatomine bite. The eastern conenose bug, Triatoma sanguisuga, was identified and tested for Trypanosoma cruzi. The insect was negative by PCR, and no additional triatomines were found in the vicinity of the home. This is the first published report of a bite from $T$. sanguisuga in South Carolina despite the fact that triatomine vectors have been documented in the state since the 1850s, and specimens have been collected from homes in the past. Sylvatic T. cruzi reservoirs are common throughout the southeastern United States, and this case brings to light the possibility of human contact with infected triatomines in the state of South Carolina for public health and clinical and entomology professionals.
\end{abstract}

In June 2019, a 51 year-old Hispanic woman was sitting on a bed leaned against a wall in an upstairs bedroom when she felt something crawling on her upper left arm. She discovered four insect bites and a triatomine insect still on her arm (later saved at room temperature in a bottle), Figure 1. The woman and her husband were visiting relatives living in Dorchester County, $\mathrm{SC}$. The woman recognized the insect as the vector for the causative agent of Chagas disease from her home country of Colombia, but realized it was a different species as indicated by her comment that the current triatomine was "black with red markings instead of brown (like in Colombia)," Figure 2. After discussing the bite with the homeowners, the family requested assistance from local authorities. A collaborative investigation between the state public health entomologist, the University of South Carolina, and the CDC's Division of Parasitic Diseases and Malaria was initiated.

All house occupants $(n=5)$ screened negative for Trypanosoma cruzi antibodies by Chagas STAT-PAK ${ }^{\circledR}$ (Chembio, Medford, NY); additional whole blood samples were not available for additional diagnostics. This was the first notable triatomine encounter according to the homeowners. Domestic opportunities for triatomine intrusion were considered low risk: home in good condition, "never" left doors or windows open, no exterior cracks, and no pets. Potential residential triatomine habitats included the home's pier and beam foundation with lattice perimeter, the rural surrounding area with sylvatic animals present, and two large unused wood piles immediately adjacent to the homeowner's property line, Figure 3. An additional investigation into these wood piles did not reveal any triatomines. However, these wood piles were noted as appropriate sites for rodents and marsupials, which are frequently colonized by triatomines in the United States and act as reservoir hosts for $T$. cruzi. ${ }^{1}$ Furthermore, two attempts to collect additional triatomines at the residence were executed, but both attempts were during or directly following heavy rain events, which are adverse collection conditions for triatomines. $^{2,3}$ The bite-associated triatomine was morphologically identified as an adult female Triatoma sanguisuga, the eastern conenose bug, using a dichotomous key. ${ }^{4}$ The insect

*Address correspondence to Kyndall C. Dye-Braumuller, Public Health Research Center, 921 Assembly St., Rm. 417, Columbia, SC 29208-0001. E-mail: kyndallb@email.sc.edu was $T$. cruzi DNA negative by PCR performed at the CDC's Division of Parasitic Diseases and Malaria.

This finding is the first published case report of a T. sanguisuga bite in South Carolina. Approximately 35 Triatoma specimens from 14 counties are housed in state insect collections, dating back to 1934 (M. Ferro and M. Gibson, personal communication). Two $T$. sanguisuga from the Clemson Arthropod Collection were involved in biting humans in Hampton and Jasper counties in the 1990s, and one was found on a bed inside a domicile; however, $T$. cruzi testing was not performed (M. Ferro, personal communication). As recently as August 2019 , three T. sanguisuga kissing bugs were submitted to the state health department from Jasper County, SC, with no reported bites to humans (C. L. Evans, unpublished data).

Triatoma lecticularia and $T$. sanguisuga are historically published vectors dating to 1859 , when $T$. lecticularia was noted in "the Carolinas," and one T. lecticularia was identified in Kershaw County, SC, in 1961 (Mike Ferro, personal communication). Triatoma sanguisuga has been identified in the state as recently as 2002 (M. Ferro, personal communication). Both $T$. sanguisuga and $T$. lecticularia have also been documented in the surrounding states: Georgia, North Carolina, and Tennessee in both domestic and peri-domestic environments. ${ }^{1}$ The fifth reported autochthonous case of Chagas disease in the United States was reported in neighboring rural Tennessee in 1999. ${ }^{6}$ Triatoma sanguisuga was implicated as the vector for

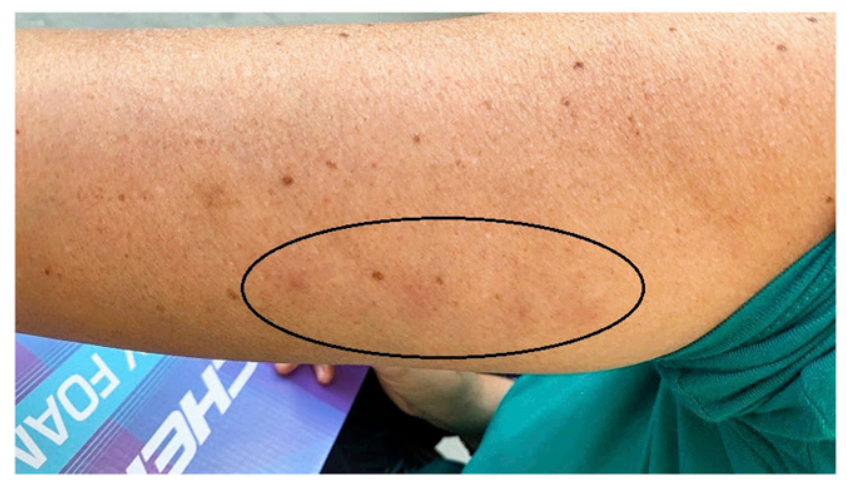

FIGURE 1. An image of the victim's arm following the triatomine bites. Note the red areas (circled) where the skin is red and raised. This figure appears in color at www.ajtmh.org. 


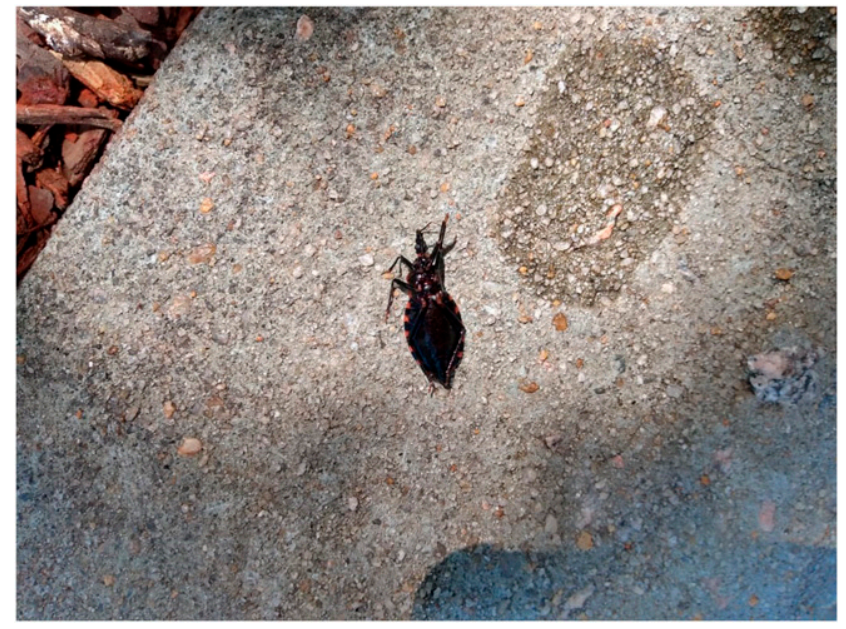

FIGURE 2. The triatomine immediately after it was discovered and killed by the house occupants. This is an image of the ventral side of the triatomine. This figure appears in color at www.ajtmh.org.

this case; additional specimens were found around the patient's home, as well as T. cruzi-positive raccoons and a dog. ${ }^{6}$

Sylvatic transmission has also been documented in South Carolina and surrounding states. Multiple studies have targeted raccoons for parasite detection; a relatively high percentage of these hosts have frequently tested positive

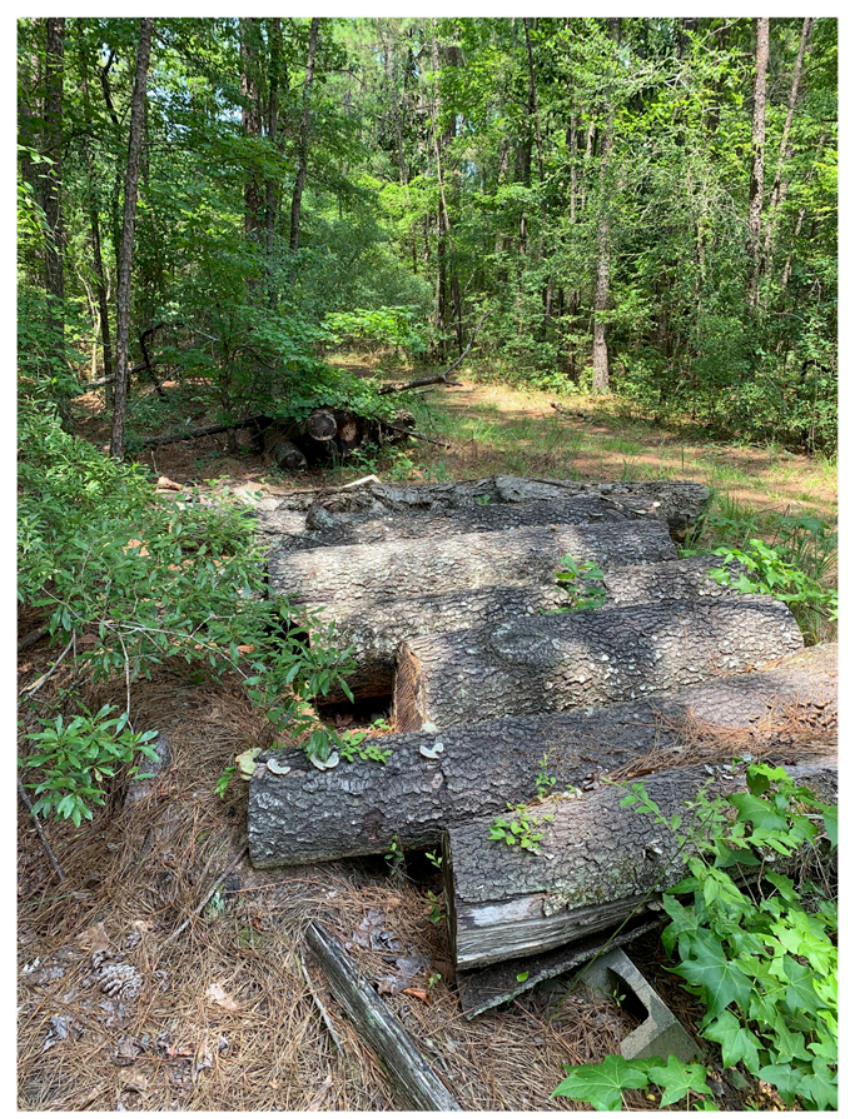

FIGURE 3. One of the large wood piles adjacent to the property line of the homeowner. These tree trunks provide an appropriate environment for various peri-domestic animals such as rodents and marsupials. This figure appears in color at www.ajtmh.org. for T. cruzi in Georgia, ${ }^{7-12}$ South Carolina, ${ }^{12}$ North Carolina, ${ }^{13}$ and Tennessee. ${ }^{6,14}$ A 2002 raccoon surveillance program in Georgia and South Carolina indicated animals captured in cities and coastal regions had statistically higher infection prevalence than those from rural and inland areas. ${ }^{12}$ Additional peri-domestic animals that have tested positive for $T$. cruzi in Georgia include opossums, ${ }^{7,8,10,15}$ striped skunks, ${ }^{7,10}$ gray foxes, ${ }^{7}$ coyotes, ${ }^{10}$ and bobcats. ${ }^{10}$ Wild opossums in North Carolina have also tested positive for the parasite. ${ }^{13}$ In addition, a 2007 study demonstrated a low $T$. cruzi prevalence in wild canids from SC Aiken and Barnwell counties. ${ }^{16}$ Overall, our report indicates that triatomines should be of interest to public health professionals in the southeastern U.S. coastal region, especially for those who move into sylvatic host animal habitats where risk for contact with infected vectors significantly increases. $^{1}$

Received January 16, 2020. Accepted for publication May 26, 2020. Published online August 3, 2020.

Acknowledgments: We would like to thank Gena Lawrence, Susan Montgomery, Division of Parasitic Diseases and Malaria, Center for Global Health; Mike Ferro, Clemson University Arthropod Collection; and Matthew Gibson, the Charleston Museum.

Financial support: A portion of this work was funded by the Brockman Medical Research Foundation, although they had no direct involvement in the study design, interpretation, or reporting.

Authors' addresses: Kyndall C. Dye-Braumuller, Mary K. Lynn, and Melissa S. Nolan, Laboratory of Vector-Borne and Parasitic Diseases, Arnold School of Public Health, University of South Carolina, Columbia, SC, E-mails: kyndallb@email.sc.edu, mklynn@mailbox.sc. edu, and msnolan@mailbox.sc.edu. Chris L. Evans, South Carolina Department of Health and Environmental Control, Bureau of Laboratories, Columbia, SC, E-mail: evanscl@dhec.sc.gov. Colin J. Forsyth, DNDi North America, New York, NY, E-mail: cforsyth@dndi.org. Claudia Gomez, Secretaria de Salud Departamental, Bogotá, Colombia, E-mail: claudiaagomezm08@gmail.com.

This is an open-access article distributed under the terms of the Creative Commons Attribution (CC-BY) License, which permits unrestricted use, distribution, and reproduction in any medium, provided the original author and source are credited.

\section{REFERENCES}

1. Bern C, Kjos S, Yabsley MJ, Montgomery SP, 2011. Trypanosoma cruzi and Chagas' disease in the United States. Clin Microbiol Rev 24: 655-681.

2. Ekkens DB, 1981. Nocturnal flights of Triatoma (Hemiptera: Reduviidae) in Sabino Canyon, Arizona: I. light collections. J Med Entomol 18: 211-227.

3. Vazquez-Prokopec GM, Ceballos LA, Kitron U, Gürtler RE, 2004. Active dispersal of natural populations of Triatoma infestans (Hemiptera: Reduviidae) in rural northwestern Argentina. $J$ Med Entomol 41: 614-621.

4. Lent H, Wygodzinsky $P, 1979$. Revision of the Triatominae (Hemiptera, Reduviidae), and their significance as vectors of Chagas' disease. Bull Am Mus Nat Hist 163: 123-520.

5. Ryckman RE, Ryckman JV, 1967. Epizootiology of Trypanosoma cruzi in southwestern North America Part XII: does Gause's rule apply to the ectoparasitic Triatominae? (Hemiptera: Reduviidae) (Kinetoplastidae: Trypanosomidae) (Rodentia: Cricetidae). J Med Entomol 4: 379-386.

6. Herwaldt B, Grijalva M, Newsome A, McGhee C, Powell M, Nemec D, Steurer F, Eberhard M, 1999. Use of PCR to diagnose the fifth reported US case of autochthonous transmission of Trypanosoma Cruzi-Tennessee, 1998. Am J Trop Med Hyg 61: 564.

7. McKeever S, Gorman GW, Norman L, 1958. Occurrence of a Trypanosoma cruzi-like organism in some mammals from 
southwestern Georgia and northwestern Florida. J Parasitol 44: 583-587.

8. Pung OJ, Banks CW, Jones DN, Krissinger MW, 1995. Trypanosoma cruzi in wild raccoons, opossums, and triatomine bugs in southeast Georgia, USA. J Parasitol 81: 324-326.

9. Pietrzak SM, Pung OJ, 1998. Trypanosomiasis in raccoons from Georgia. J Wildl Dis 34: 132-136.

10. Brown EL, Roellig DM, Gompper ME, Monello RJ, Wenning KM, Gabriel MW, Yabsley MJ, 2010. Seroprevalence of Trypanosoma cruzi among eleven potential reservoir species from six states across the southern United States. Vector-Borne Zoonotic Dis 10: 757-763.

11. Schaffer G, Hanson W, Davidson W, Nettles V, 1978. Hematotropic parasites of translocated raccoons in the southeast. J Am Vet Med Assoc 173: 1148-1151.
12. Yabsley MJ, Noblet GP, 2002. Seroprevalence of Trypanosoma cruzi in raccoons from South Carolina and Georgia. J Wildl Dis 38: 75-83.

13. Karsten V, Davis C, Kuhn R, 1992. Trypanosoma cruzi in wild raccoons and opossums in North Carolina. J Parasitol 78: 547-549.

14. Maloney J, Newsome A, Huang J, Kirby J, Kranz M, Wateska A, Dunlap B, Yabsley MJ, Dunn JR, Jones TF, 2010. Seroprevalence of Trypanosoma cruzi in raccoons from Tennessee. J Parasitol 96: 353-358.

15. Parrish EA, Mead AJ, 2010. Determining the prevalence of Trypanosoma cruzi in road-killed opossums (Didelphis virginiana) from Baldwin county, Georgia, using polymerase chain reaction. Ga J Sci 68: 132.

16. Rosypal AC, Tidwell RR, Lindsay DS, 2007. Prevalence of antibodies to Leishmania infantum and Trypanosoma cruzi in wild canids from South Carolina. J Parasitol 93: 955-958. 